The Influence of the Density Inside a Train Carriage on Passenger Boarding Rate Nattanon Luangboriboon ${ }^{\mathrm{a}^{*}}$, Sebastian Seriani ${ }^{\mathrm{b}}$ and Taku Fujiyama ${ }^{\mathrm{a}}$

${ }^{a}$ University College London, United Kingdom, Civil Environmental and Geomatic Engineering

${ }^{\mathrm{b}}$ Universidad de los Andes, Chile, Faculty of Engineering and Applied Sciences

Contact: Nattanon Luangboriboon, ucesnlu@ucl.ac.uk, Civil Environmental and Geomatic Engineering, University College London, Chadwick Building, Gower St., London, WC1E 6BT, UK 


\section{The Influence of the Density Inside a Train Carriage on Passenger Boarding Rate}

Passenger alighting and boarding time is an important factor for crowded metros with high frequency operations. Some operators leave the train doors open until the last passenger boards or passengers voluntarily stop boarding, while others regulate the boarding process. To evaluate whether it is effective to regulate the passenger while boarding or not, this research explores how the density inside the train would influence the passenger boarding rate by conducting a laboratory experiment. The results showed that the passenger boarding rate increased as the density increased, up to approximately $2.5-3.0$ passengers $/ \mathrm{m}^{2}$. Beyond that point, our results suggested that the boarding rate may have decreased, but the evidence was not conclusive. It is deduced that, under the experimented density (up to around 5 passengers $/ \mathrm{m}^{2}$ ), the density does not have any apparent negative effects on the boarding rate, which implies that there is no strong evidence to recommend passenger boarding regulation.

Keywords: passenger; density; boarding rate; experiment

\section{Introduction}

\section{$1.1 \quad$ Background}

The demand for travel on metros around the world has been continuously growing. According to [1], the demand for travel on the London Underground (LU) increased by more than 10 percent from 2012 to 2017 . As modern signalling systems allow services to operate at a high frequency, one of the main factors which limits networks capacities is no longer signalling system issues but the train dwell time at stations [2,3]. Currently, many railway operators use a fixed value for the dwell time at stations in planning, e.g. 20 seconds for most stations in the Bangkok Transit System (BTS). In reality, unless the platform is staffed with platform stewards who stop passengers from boarding at the departure time, doors are often left open until the last passenger boards the train or passengers stop boarding because of overcrowding inside the carriage. Therefore, the actual dwell times are often different from those of the planned timetables, thereby 
causing delays in services. In the case of LU's Victoria line, because the morning peak operation has a headway of less than 120 seconds (36 trains per hour), an excess dwell time of only few seconds can significantly affect the operation of the line. Accurately predicting required dwell times and developing timetables based on them would increase the service reliability and quality for metro systems.

One of the major components which determines the train dwell time is the passenger boarding and alighting time [4]. Passenger boarding and alighting times at a platform are affected by many factors, among which passenger flow rate is one of the most significant [5]. In some previous research, the passenger boarding and alighting rate has been assumed to be constant (see the literature review section of this article). However, this does not reflect reality, since the passenger flow rate may vary due to many factors, e.g. the physical design of the trains and platforms, the density inside the vehicle, the platform density and the number of passengers boarding and alighting [2]. Among such factors, crowding has been found to affect passenger behaviour: passenger walking speed is influenced by an overcrowding situation in that it tends to decrease when the density is high, which in turn increases the passenger boarding and alighting time [6-8]. It was suggested that there is a non-linear relationship between passenger boarding rate and the density inside the vehicle $[9,10]$. However, this impact of crowding, especially in a train carriage, has not been thoroughly investigated in previous work.

This non-linear relationship would indeed have many implications for operations. While some train operators allow passengers to board already fully-crowded carriages, if the boarding rate decreases after the crowding reaches a certain point and the next train is waiting outside the station for the platform to become vacant, it can be more efficient (i.e. more passengers can be transported in a given time by the system) to stop passengers in the middle of boarding process to let the (current) train run out and the next train run 
in. A better understanding of the relationship between density and passenger boarding rate would allow a better boarding strategy and more accurate prediction of the boarding time in the train service planning process.

This paper is composed of five sections, including this introduction, in which the context, the aims and objectives are explained. The next section provides a review of literature related to this research. The methodology section describes the experiment method including the experiment setup and the data analysis methods. The fourth section presents the results of the experiment. Finally, discussion and conclusion of the findings are presented. Additionally, recommendations for practical implication and future work are also provided.

\subsection{Aims and Objectives}

This research aims to investigate the relationship between the density inside the train and the passenger boarding rate. The better understanding of this relationship would provide a basis for developing an accurate dwell time prediction model. Additionally, it could be used to identify the cut-off point, in the case of regulate boarding strategy, or whether it is not worth regulating the boarding process.

The following objectives are defined: a) review existing studies about dwell time, passengers dynamics/behaviour and boarding rate; b) define the experiment setup at the laboratory facility; c) simulate the boarding and alighting of passengers using the defined experiment setup; d) analyse the effect of the density inside the train on the boarding rate; e) suggest some recommendations for further research.

\section{Literature Review}

The existing research relevant to this study can be categorized into three sections, namely: the dwell time, the pedestrian dynamics and passenger behaviour in crowded conditions, and the passenger flow rate at the platform-train interface (PTI). Firstly, the principle of 
the dwell time and its components are reviewed, followed by the development of the dwell time estimation models. The next section reviews the literature on pedestrian dynamics and effect of crowding on walking behaviour. In the third section, passenger behaviour at PTI is reviewed. Finally, the research gap and the contribution of this research will be discussed.

\subsection{Review of research on dwell time}

One common approach to increase the capacity of metro systems is to increase their service frequency. However, train service frequency is limited by the train headway. The headway is governed by two major components, which are the Run-out-run-in time (RORIT) and the dwell time [5]. While the RORIT is restricted by the signalling system and the train performance which are hard to change, dwell time can be managed in order to reduce the train headway [5]. The train dwell time is governed by the door opening and closing time, the number of passengers boarding and alighting and the time each passenger takes to board and alight [11,12]. Furthermore, there are a number of factors which affect the passenger boarding and alighting time, e.g. physical constraints of the trains and the platforms, the number of passengers on board and on the platform, operational constraints and passenger behaviour [5].

The principle of dwell time and its components have been studied by several researchers. For instance, Fröidh, Kottenhoff and Andersson [13] studied train layouts to discover which would allow punctual stops at stations at peak load and allow boarding and alighting in a small time frame. Yazdani et al. [14] also found that the seat allocation (e.g. assigning groups of seats to a specific group of passengers) could affect the dwell time in rail systems, which is also related to safety conditions for passengers and takes into consideration different design layouts inside the train [15]. In addition, there are extensive studies on the factors which affect the dwell time, and a number of models were 
developed in order to accurately predict the train dwell time at stations. Lin and Wilson [16] performed a study on a light rail system in Massachusetts and developed a train dwell time model. The model developed was a function of the number of boarding, alighting and on-board passengers. Similarly, Puong [10] proposed a dwell time model based on observation at train stations. Puong's model shows that the dwell time increases linearly with the number of passengers boarding and alighting and non-linearly with the number of passengers on board [10]. For LU, Weston and McKenna [17] suggested the Train Service Model formula, used to estimate the dwell time. In this model, the station stop time is a function of the number of boarding and alighting passengers, the number of doors, the number of seats, the peak door/average door factor and the number of through passengers. This formula was widely used in a number of studies; however, it was found that the formula does not perform well at higher passenger load $[2,18]$. Similarly, there are several other research attempts to create a dwell time prediction model [12,19-23]. Despite many researchers developing dwell time models, these models are not generic and are limited to the context in which they were developed [24]. However, it can be seen that, in most of the models developed, passengers are one major aspect which contributed to the train dwell time. The number of boarding and alighting passengers and throughpassengers were included in the majority of these models [25].

Although there are important advances in the literature, most of these models are based on existing stations, which limits the analysis only to the trains and platforms that currently exist, without being able to test other configurations. To solve the problem presented by field observations, other studies based on real-scale experiments have allowed testing different station configurations to reduce the dwell time and improve efficiency and safety at the PTI. Fernandez et al. [26] reported that the dwell time depends not only on the number of passengers boarding and alighting, but also on the platform 
height, door width, fare collection method, internal layout of the vehicle, and occupancy of the vehicle. Another experiment done by Rudloff et al. [27] showed that the dwell time decreased as the door width increased, reaching a minimum overall value of $24.93 \mathrm{~s}$ for a door 1,850 $\mathrm{mm}$ wide. Fujiyama, Thoreau and Tyler [29] reported that a $50 \mathrm{~mm}$ vertical gap achieved a maximum flow at the doors of 1.42 passenger/s (for a $1,800 \mathrm{~mm}$ door width and a setback of $800 \mathrm{~mm}$ ). Similarly, Fernández, Valencia and Seriani [30] found that the vertical gap should be reduced to $150 \mathrm{~mm}$ or less, enabling a door capacity of 1.0 passenger/s-m in the case of a door width of $1,650 \mathrm{~mm}$. Another experiment [31] recommended using platform humps to produce a level access (vertical gap of $0 \mathrm{~mm}$ ) on parts of platforms. According to [32] the use of steps has also affected the dwell time, in that boarding passengers spent more time ( $4.13 \mathrm{~s}$ on average) than those who were alighting ( $3.68 \mathrm{~s}$ on average). The authors found that $40 \%$ of the total passengers found it difficult to complete the process of boarding and alighting. Previously, Daamen, Lee and Wiggenraad [33] found that the flow rate at the doors decreased from 0.91 passenger/s to 0.81 passenger/s when the step was changed from $50 \mathrm{~mm}$ (level access) to $400 \mathrm{~mm} \mathrm{(2}$ steps). In this experiment the horizontal gap was $50 \mathrm{~mm}$ and the door width $800 \mathrm{~mm}$. Recently, some authors [34-37] reported that platform edge doors have no important impact on the dwell time, but the interaction is influenced by other variables such as the formation of lines of flow, distance between passengers, speed and space used by each passenger.

\subsection{Review of research on pedestrian dynamics and passenger behaviour in crowded situations}

The basis of research on passenger boarding and alighting speed lies in the research on pedestrian walking behaviour. Fruin [38] and Tregenza [8] are probably the first researchers to investigate the relationships between density and pedestrian walking speed based on observations and experiments respectively. Their research shows that at higher 
crowd density, the mean walking speed tends to decrease. There has been much research into this topic area, and one important issue which has been studied by many researchers is the relationship between pedestrian speed, flow and density, also known as pedestrian flow fundamental diagram [39-46].

There has been some research on the situation in which many pedestrians evacuate through a narrow doorway/corridor [47-49]; however, passenger boarding into a crowded carriage is slightly different from this phenomenon. At the PTI the space after the narrow door is limited and passengers would stay in the carriage, while in evacuation once people pass through the narrow door, they walk into an unlimited space beyond the door.

In addition, there has been some research that has proposed methods to model passenger walking behaviour in public transport facilities [50-56]. Within the research on railways, some have investigated passenger behaviour in crowded conditions. Lam et al. [57] classified congestion on the platform and inside the train using the Level of Service scale and developed a binary logit model to measure the discomfort of passengers. According to RSSB research on the management of on-train crowding [58], it was found that factors which affect passenger behaviour can be divided into four main categories: people, physical, information and environmental. In railway systems, the presence of other people is the greatest influencing factor on passenger behaviour. According to [6,59], crowding at the platform area can critically affect the passenger behaviour and passenger distribution on platform and carriage, which in turn affects the trains dwell time and the network capacity. Pel, Bel and Pieters [7] also found that crowding may cause passengers to adapt their travel behaviour. The lack of space can result in physical discomfort which increases stress and reduces productivity. For pedestrians, if the crowd density reaches a certain level, the density becomes one significant factor which governs 
their walking speed. However, each type of passenger adapts to each crowding level differently, varied by the journey purpose and the station of origin [60].

In the case of $\mathrm{LU}$, the acceptable maximum crowding level is 5 passengers per sq meter [5]. However, while walking, if the number of passengers exceeds 2 passengers per sq meter, it is considered crowded [61]. In order to understand the boarding and alighting time of passengers, one of the issues which needs to be investigated is the effect of density and crowding on passenger flow rate.

\subsection{Review of research on passenger flow rate at the PTI}

It can be noted that the existing research on pedestrian dynamics suggests that passenger density would affect the speed, and thus the alighting and boarding flow rates at PTI may not be constant during the whole alighting and boarding process. Nevertheless, previous research has tended to show an average passenger flow rate only. Wiggenraad [62] observed an average flow rate of around 1 passenger per second at Dutch railway stations, while [2] observed a boarding rate of 0.87 passengers per second at Clapham Junction. Arup [63] also observed a similar boarding rate of 0.82 passengers per second at Farringdon station. The approach of showing average flow rates only may be reasonable because in order to show the detailed relationship between the density and speed, it is necessary to record not only the number of boarders and alighters at the PTI but also the number of passengers on the train at each time step, which is essentially a difficult task. In fact, Puong [10] and Lee, Daamen and Wiggenraad [9] performed an empirical experiment in actual situations and found a non-linear relationship between the boarding rate of passengers and the number of passengers inside the vehicle. The relationship shows that below certain levels of density, the density does not significantly affect the boarding rate, but the boarding rate will decrease as the density increases when the density exceeds a drop-off point. In addition, [64] study on buses found that crowding at the 
platform areas may cause the dwell time model to be less accurate.

\subsection{Research Gap and Main Contribution}

Although there are number of research focus on the passenger flow rate at PTI, only $[9,10]$ show a non-linear relationship between the density inside vehicle and boarding rate. Both research $[9,10]$ were performed empirically in an actual situation, where many factors cannot be controlled. This study aims to investigate into this non-linear relationship by mean of laboratory experiment. By better understanding this relationship between the train density and passenger boarding rate, it would contribute more or less in the research area of passenger flow rate study $[9,10]$ and dwell time prediction $[2,12,17]$. Railway operation could be planned and design better which will benefit both passenger and operator.

\section{Method}

\subsection{Experiment Setup}

Due to the limitations of the existing vehicle types and platform layouts, it is not possible to control all the factors which, in turn, make it impossible to investigate a complete range of situations. Therefore, several laboratory experiments are performed, including the Pedestrian Accessibility Movement Environment Laboratory (PAMELA). In a laboratory, certain variables can be changed while keeping the others constant, which allows the study of the influence of a single factor $[35,37,65]$. A series of experiments were conducted at the PAMELA using a full-size mock-up train carriage and a platform in order to obtain empirical evidence for the passenger boarding activities. The layout of the train and the platform and major variables were configured to be in line with a real railway project in the UK. 
The mock-up represented a half of the proposed carriage with the same dimensions (i.e. scale 1:1). Figure 1illustrates the layout of the mock-up carriage. As indicated, the width of the carriage was $2,500 \mathrm{~mm}$, and the length was $10,000 \mathrm{~mm}$. However, the door width and the vestibule setback, as indicated in Figure 1, varied in each experiment. The door width was set to be $1,300 \mathrm{~mm}, 1,500 \mathrm{~mm}$ and $1,800 \mathrm{~mm}$ while the vestibule setback (distance between the seats and the train doors) was set to be $0 \mathrm{~mm}$, $400 \mathrm{~mm}$, and $800 \mathrm{~mm}$, depending on each experiment setup. These are the values that are currently used on the railway network in Great Britain or are being considered for future rolling stock. Another factor which was varied in these experiments was the vertical difference (height from the platform to the train), of 50mm, $165 \mathrm{~mm}$ and $250 \mathrm{~mm}$, which are the values that were identified as typical in the preliminary survey of this research project. Therefore, there were a total of $27(3 \times 3 \times 3)$ setup combinations for the experiments. Two experiment runs were conducted for each combination.During each experiment, 50 participants were asked to board and alight the train, of which, in this research, 45 participants were boarding while 5 were alighting. These numbers were based on demand projection for the actual railway project to which this research was attached. There are some passengers remain on-board in each experiment to simulate the through passenger. The number of on-board passengers varied in each experiment. The door open time was set to be 27 seconds, measured from when the door was fully open until it started to close. The 27 second measurement was calculated based on the proposed future frequency (headway being 2.00 minutes), the proposed signal systems and rolling stock for the actual railway projects. Participants heard the door close alarm sound 2 seconds before the doors started closing, which is in line with the current practice of the railways in Great Britain. 
The experiments were recorded by video cameras which recorded passenger occupancy and movement on board, on the platform and at the doorway area. From these recordings, we could obtain the time each passenger boarded/alighted from the train, which could be used to calculate the passenger boarding rate [passenger/s], see Equation (1). In addition, the density [passenger $/ \mathrm{m}^{2}$ ], see also Equation (2), inside the carriage and on the platform could be obtained from the passenger occupancy.

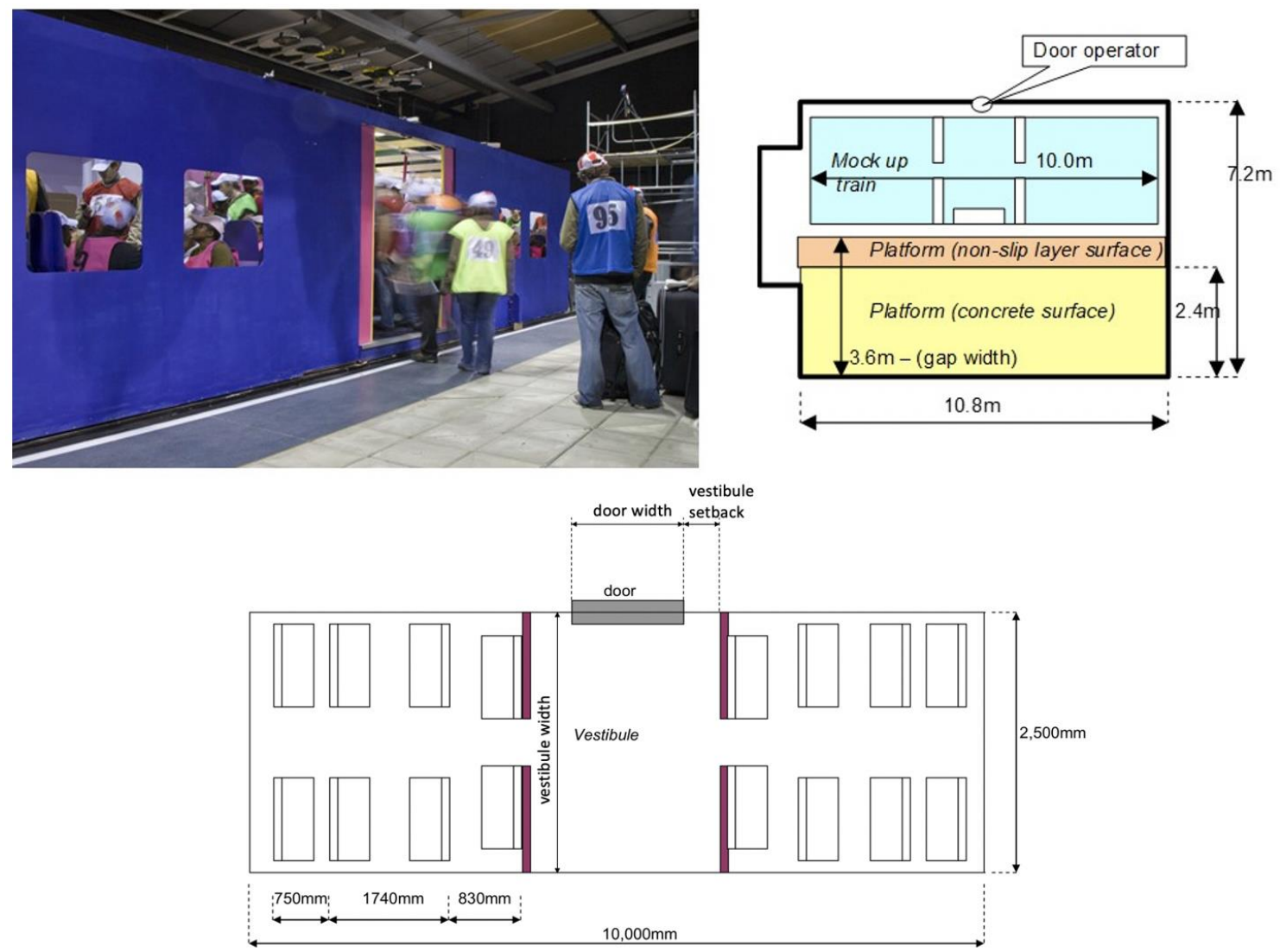

Figure 1. Mock-up Carriage Layout [29]

\subsection{Participants}

Participants were recruited from commuters, with mixture of people who were both familiar and unfamiliar with the set up. During the five days of the experiment, some participants attended just one day while some attended all five days of the experiment. Each day approximately 120 participants attended the experiment, of which $55 \%$ were male and the rest were female. The participant age varied from less than 19 years old to 
over 70. The participant age distribution in each day of the experiment is shown in Figure 2. These numbers varied depending on the day of the experiment. Participants were instructed to wear clothing and shoes similar to when they normally commute on trains. If bags were carried on an ordinary day, participants were supposed to carry them during the experiments. In addition, 12 participants were randomly selected in each experiment to carry a suitcase. However, the cases were not weighted as full cases for health and safety reasons.

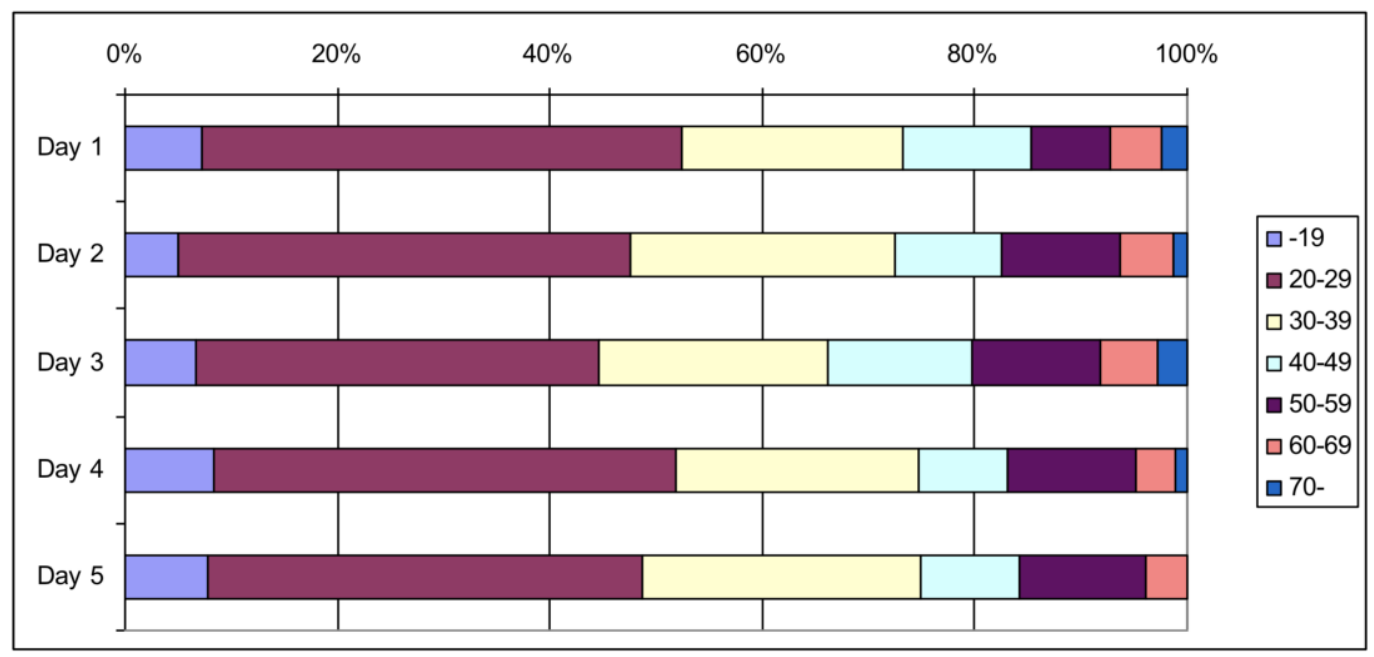

Figure 2. Participants Age Distribution [29]

\subsection{Boarding Rate and Density Calculation}

In order to observe the change of passenger boarding rate in relation to the vestibule density, boarding rates were calculated during each time interval. The boarding rate is the average boarding rate in each 5 s interval. The 5 s interval was based on Fujiyama, Nowers and Tyler's [29] experiment report. Also, with an interval smaller than 5s, there would be a high variance in the data. Also, since each experiment lasted approximately 30s, with an interval larger than 5s there would be too few intervals to investigate the behaviour. The boarding rate was calculated using the following Equation (1). The total number of passengers in each $5 \mathrm{~s}$ interval, $i_{t}-i_{t-5}$, was divided by the time length $(5 \mathrm{~s})$ to obtain the 
average boarding rate during that time interval, where $i_{t}$ is the number of passenger boarded the train from door opening until $t$ second.

$$
B r_{(t-(t-5))}=\frac{i_{t}-i_{t-5}}{5} \quad\left[\frac{\text { passenger }}{s}\right]
$$

The boarding rate of passengers was compared with the density inside the vehicle. However, for simplification, the density of the vestibule area $(D)$ was used to represent the density inside the carriage. The vestibule area is indicated in Figure 1. The vestibule density could then be calculated using Equation (2).

$$
D=\frac{\text { no.of passenger in vestibule area }}{\text { vestibule width } \times[\text { door width }+(2 \times \text { vestibule setback })]} \quad\left[\frac{\text { passenger }}{m^{2}}\right]
$$

\section{Results}

The boarding rate and vestibule density were compared against the time from door opening, as shown in Figure 3. In Figure 3both the average value of passenger boarding rate and the average vestibule density in each 5 s interval were plotted against the time from door opening. The data before the $2^{\text {nd }} \mathrm{s}$ and $27^{\text {th }} \mathrm{s}$ onward were omitted to minimize the effect of door opening and closing on the boarding behaviour. Since during these experiments the majority of passengers were boarding the vehicle (45 boarding passengers and 5 alighting passengers), the number of passengers inside the carriage therefore increased continuously from door opening until it closed. Thereby, the density increased as the time proceeded, as can be noticed in Figure 3. On the other hand, the passenger boarding rate showed a different behaviour. During the first phase of the experiment (up to approximately $12^{\text {th }}-17^{\text {th }} \mathrm{s}$ ), the boarding rate increased as the time proceeded. However, in the second phase of the experiment (from approximately $12^{\text {th }}$ $17^{\text {th }}$ s onward), the boarding rate started to decrease. 
In addition, the flow-density relationship in the pedestrian fundamental diagram (see Section 2.2) shows that the flow rate decreased after the density exceeded a certain point. This could be a possible explanation for the decreasing passenger boarding rate in the second phase of the data. In this case, as shown in Figure 3, as the density reached the value of approximately 2.5 passenger $/ \mathrm{m}^{2}$, the boarding rate started to decrease.

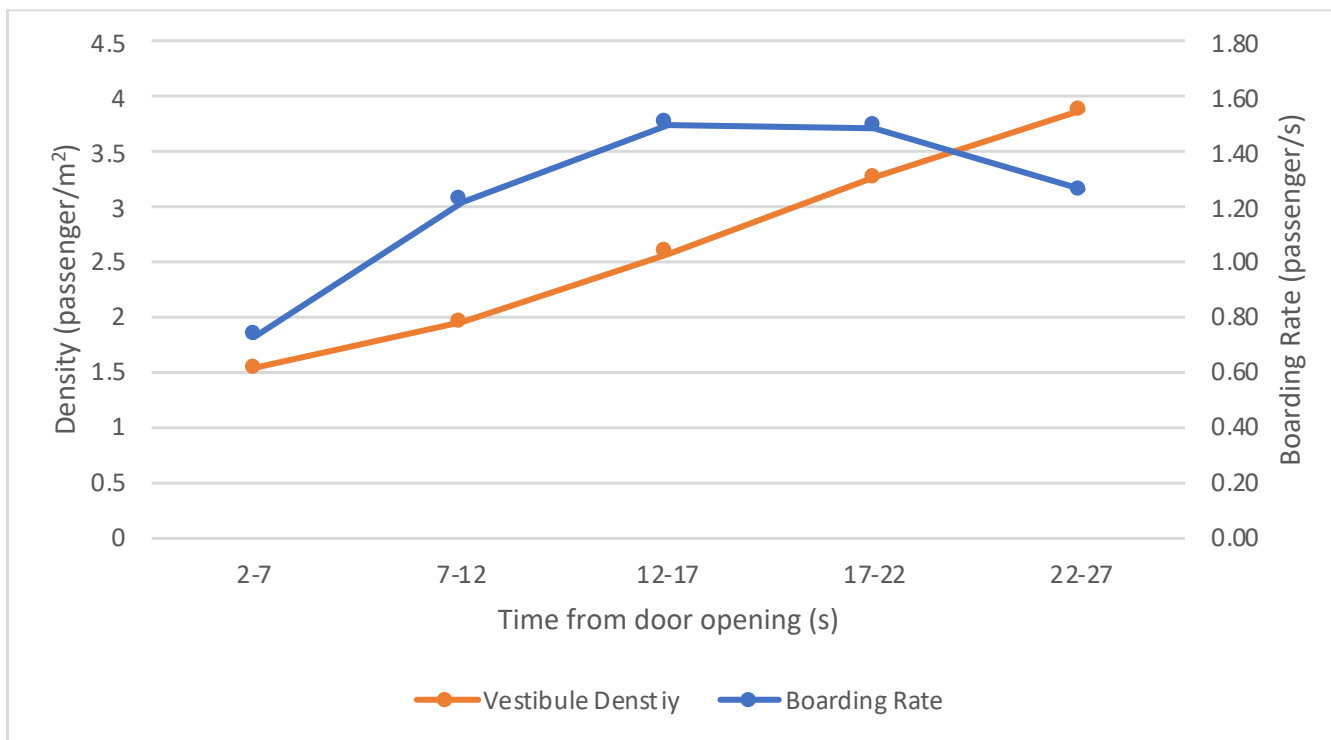

Figure 3. 5s Interval Boarding Rate and Average Vestibule Density Against the Time from Door Opening

In Figure 3 we investigated the relationship between the vestibule density and the passenger boarding rate by plotting its average value against the time from door opening. However, there might be other factors which may also affect the boarding rate. Time from door opening could be one of the factors which influenced the passenger boarding behaviour. For instance, in Figure 3, as the time approached the door closing time, the passenger boarding rate decreased at a higher rate. This might be due to the fact that some of the passengers already gave up boarding.

Figure 4 compares the boarding rate and the average density value in each $5 \mathrm{~s}$ interval from all the experiments. The data before the first $2 \mathrm{~s}$ and from $27 \mathrm{~s}$ onward are omitted due to the reason explained earlier. Figure 5 provide the same information as 
Figure 4 but in a different form. The box and whisker plot were used in Figure 5 to shows the distribution of the date, as the scatter plot in Figure 4 may be unclear on that part. As we can see from both Figure 4 and Figure 5, up to approximately 2.5 passenger $/ \mathrm{m}^{2}$, the boarding rate increase as the density increase, similar to what we observed previously in Figure 3 during the first phase (up to approximately $12-17 \mathrm{~s}$ ). Beyond 2.5 passenger $/ \mathrm{m}^{2}$, the boarding rate may seem like decreasing in Figure 4; however, the box and whisker plot (Figure 5) shows that the decreasing trend is not so clear. It was somewhat stable with some fluctuation along the way. This is different from what we observe during the second phase (from approximately $12-17$ s onward) of Figure 3.

In Figure 4 a regression analysis was performed to see the relationship between the vestibule density and the boarding rate in which a polynomial curve was assumed based on the existing work on fundamental diagrams for pedestrians (see Section 2.2). The result showed that:

$$
\text { Boarding Rate }=-0.0612 x^{2}+0.4645 x+0.5204 \quad\left(R^{2}=0.123\right)
$$

where $x$ represents density (passenger $/ \mathrm{m}^{2}$ ). Additionally, for the data of density being equal to or greater than 2.5 (passenger $/ \mathrm{m}^{2}$ ), a linear regression was performed, which yielded:

Boarding Rate $=-0.1277 x+1.8491$

$\left(R^{2}=0.0925\right)$ 


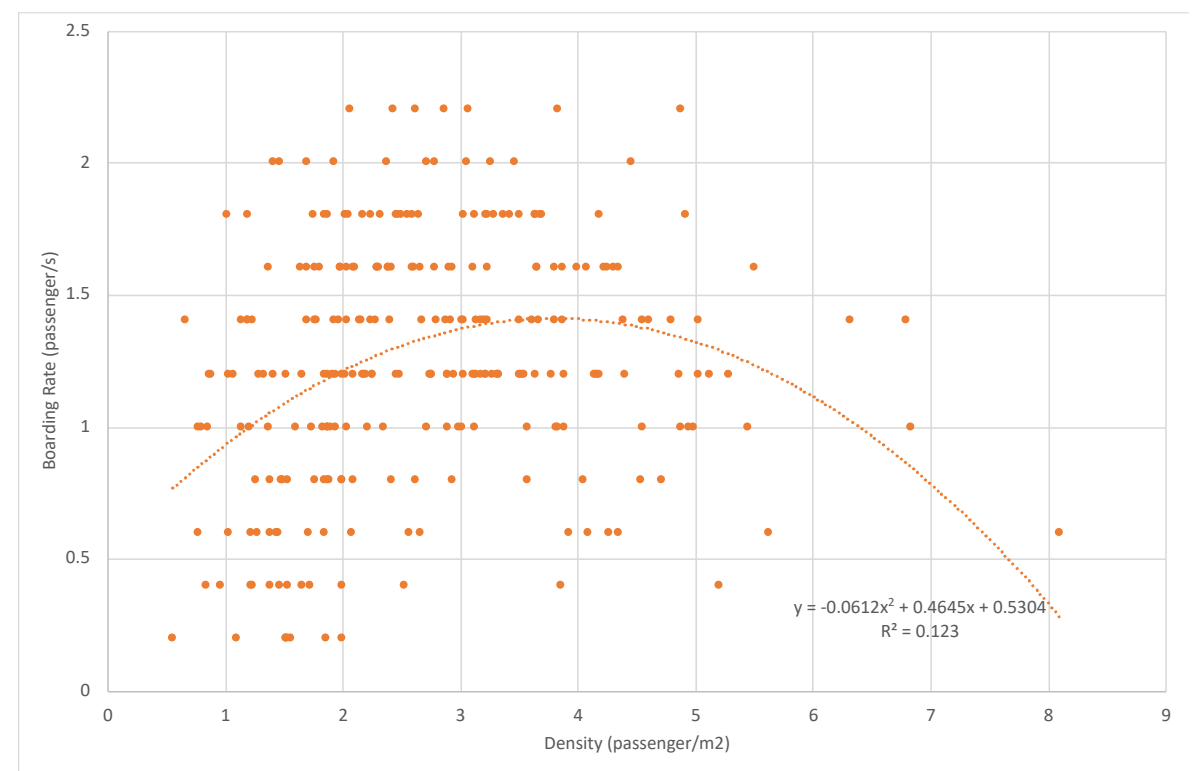

Figure 4. Vestibule Density vs Boarding Rate

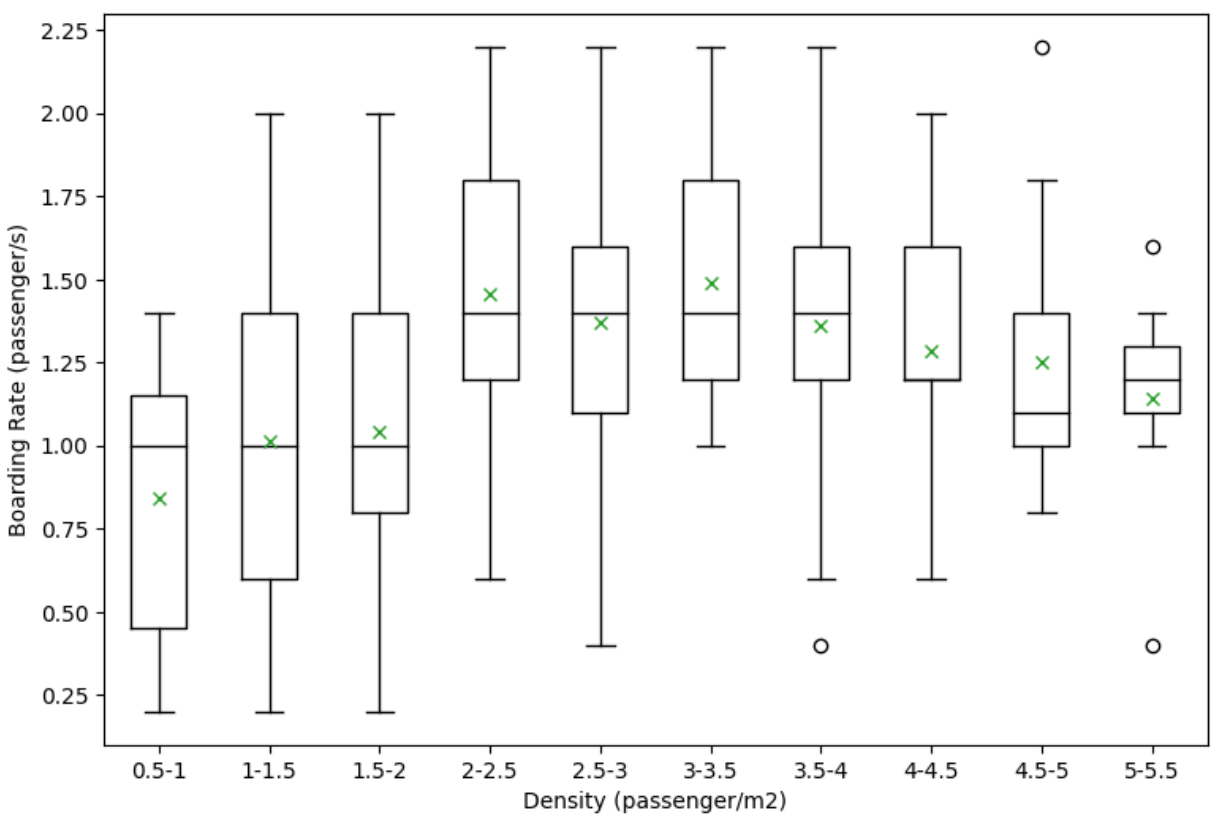

Figure 5. Box Plot of Vestibule Density vs 5s Interval Boarding Rate

In order to explicitly investigate the relationship between density and flow alone, the effect of other factors needed to be eliminated or kept to the minimum. The relationship between the vestibule density and the passenger boarding rate from every scenario was plotted separately for each time interval, to eliminate the effect of time on the behaviour, as shown in Figure 6. It can be seen that without the effect of time, there could be a tendency that after the density of around 2.5 passenger $/ \mathrm{m}^{2}$, the boarding rate 
may decrease, but there was no clear evidence that supports this.

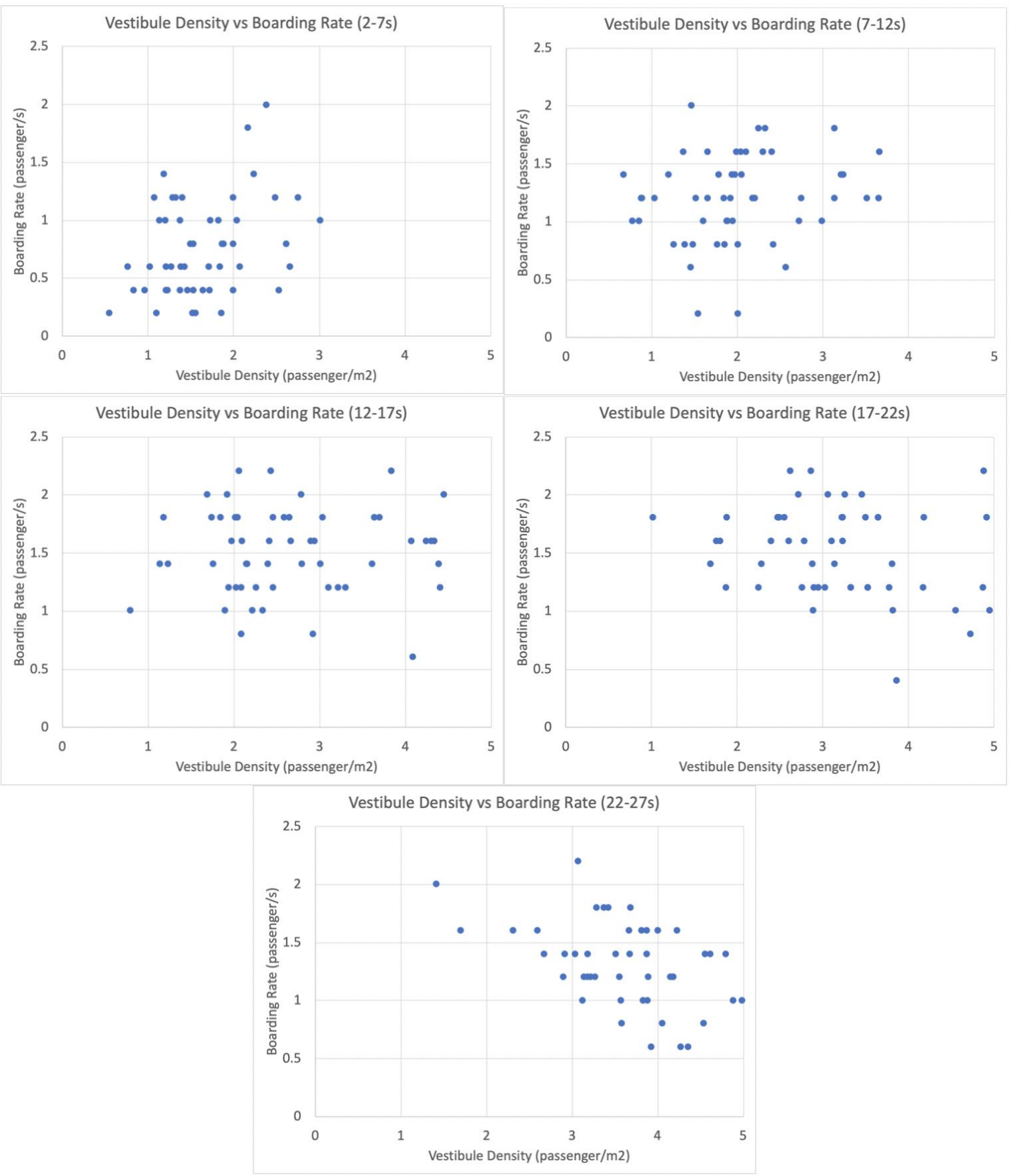

Figure 6. Vestibule Density vs Boarding Rate in Each Time Interval

\section{Discussion}

In Figure 3, it suggests that the flow rate would increase along with the density up to a certain point (approximately 2.5 passenger $/ \mathrm{m}^{2}$ ) beyond which the flow rate would start 
decreasing. One of the possible reasons behind the increasing of the boarding rate during the first phase can be explained using the pedestrian flow fundamental diagram [39-46]. Before the door opens, passengers are congested around the door area, where the speed of passengers is equal to zero. As the door opens, the passengers start to gain speed from static; therefore, the boarding rate in 2 to 7 second region is quite low. According to the speed-flow relationship in the pedestrian flow fundamental diagram [39-46], as the speed increases from zero, the flow increases as well. Additionally, it is shown by the flowdensity relationship that flow rate increases as the density increases, until the density reaches the drop-off point. It is worth noting that the density value in the fundamental diagram is the density of the pedestrian flow itself, which is a different value from the case studied in the experiments in which the density is inside the vehicle; therefore, the relationship between them might be different.

Whilst Figure 3 suggests the existence of a drop-off point (around 2.5 passenger $/ \mathrm{m}^{2}$ ) beyond which the boarding rate would decrease, Figure 4 and Figure 5 did not clearly show this. The linear regression model applied for the data beyond 2.5 passenger $/ \mathrm{m}^{2}$ in Figure 4 showed that, although the gradient was negative, the $\mathrm{r}$ square value was 0.0925 , which is insignificant. In Figure 5, the mean values decreased beyond 2.5 passenger $/ \mathrm{m}^{2}$, but it was not so clear. In Figure 6, whilst the time sector of the 22 to 27 second showed a downward trend, the time sectors of the 12 to 17 and the 17 to 22 seconds did not clearly show such a trend. It would be fair to conclude that there might be such a tendency of decrease, but within this experiment there was not enough supporting evidence.

One possible reason why the relationship was not clear could be related to the fact that the passenger movement may involve people's decisions, and therefore there are many factors, including psychological factors, that influence the passenger boarding 
behaviour $[6,7,58,60]$. This contributed to variation of the results, which obscured the relationship between the density and the boarding rate. In addition, it should be noted that in our experiment the number of data points in the region of 5 passenger $/ \mathrm{m}^{2}$ or above was fewer than that of 2.5 passenger $/ \mathrm{m}^{2}$ or above. Whilst the results of our experiment suggested with weak evidence that the drop-off point could be around 2.5 passenger $/ \mathrm{m}^{2}$, it may be the case that there is another drop-off point in the region of 5 passenger $/ \mathrm{m}^{2}$ or above.

\section{Concluding Remark}

This research has investigated the relationship between the density inside the vehicle and the passenger boarding rate. Our hypothesis was that the relationship may be non-linear, and when the density reaches a drop-off point, the boarding rate may start decreasing.

\subsection{Implication for Practice}

The results from our laboratory experiments show that whilst the boarding rate would increase along with the vestibule density up to around $2.5-3.0$ passenger $/ \mathrm{m} 2$, the relationship between them was not clear beyond that point. Practically, one could make an assumption that the boarding rate would not significantly decrease in the conditions tested (up to around 5 passenger/m2). Therefore, it can be implied that it is not necessary to implement the passenger boarding regulation strategy while the density is below 5 passenger/m2. In fact, according to LU [66], the maximum observed standing density on the LU are 5 passenger/m2. However, on high-frequency lines, if a train with exceptional density is delayed, it would cause knock-on delays to the following trains, and it would be necessary to consider exceptionally dense cases for the sake of operation reliability $[2,3,5,11,12]$.

\subsection{Limitations and Future Research}

Although laboratory experiment allows an in-depth research on an influence of a single 
variable in a complete range of situation, it may not completely reflect a real situation. The environment, instruction and other factors may influence people to behave differently. Also, the people's behaviour can be affected by many factors; hence, they may behave differently.

The result of this experiment can only be concluded up to the density of 5 passenger $/ \mathrm{m}^{2}$. The author suggests that an investigation in a higher density conditions (i.e. 5 passenger $/ \mathrm{m} 2$ or more) would be useful for the study of the relationship (between the boarding rate and the vestibule density). In an actual situation, the density might exceed this value, if the drop-off point does exist and can be identify, it would allow an efficient proactive passenger control during boarding.

\section{Disclosure statement}

The author(s) declare(s) that there is no conflict of interest regarding the publication of this paper.

\section{Acknowledgements}

This study was partially supported by ANID (Chile) Project REDES190054 and ANID (Chile) Project FONDECYT 11200012. The funder had no influence in the direction or the results of the analysis conducted.

\section{References}

[1] TfL. Annual Report and Statement of Accounts. 2018.

[2] Harris NG. Train boarding and alighting rates at high passenger loads. J. Adv. Transp. 2006;40:249-263.

[3] TRB. Highway capacity manual. 2000.

[4] Parkinson T, Fisher I. Rail transit capacity. Transportation Research Board; 1996. 
[5] TfL. Tapir Phase 1 Report.pdf. 2014.

[6] Vuchic VR. Urban public transportation; systems and technology. 1981;

[7] Pel AJ, Bel NH, Pieters M. Including passengers' response to crowding in the Dutch national train passenger assignment model. Transp. Res. Part A Policy Pract. [Internet]. 2014;66:111-126. Available from: http://dx.doi.org/10.1016/j.tra.2014.05.007.

[8] Tregenza P. The design of interior circulation : people and buildings /Peter Tregenza. London: London : Crosby Lockwood Staples; 1976.

[9] Lee Y, Daamen W, Wiggenraad P. Boarding and alighting behavior of public transport passengers. 2007.

[10] Puong A. Dwell time model and analysis for the MBTA red line. Massachusetts Inst. Technol. Res. Memo. 2000;1-10.

[11] TRB. Transit Capacity and Quality of Service Manual, Third Edition [Internet]. 2013. Available from: https://www.nap.edu/catalog/24766.

[12] Buchmueller S, Weidmann U, Nash A. Development of a dwell time calculation model for timetable planning. WIT Trans. Built Environ. 2008;103:525-534.

[13] Fröidh O, Kottenhoff K, Andersson E. Green Train concept and interior design. Int. J. Rail Transp. [Internet]. 2014;2:28-39. Available from: http://dx.doi.org/10.1080/23248378.2013.878293.

[14] Yazdani D, Omidvar MN, Deplano I, et al. Real-time seat allocation for minimizing boarding/alighting time and improving quality of service and safety for passengers. Transp. Res. Part C Emerg. Technol. [Internet]. 2019;103:158173. Available from: https://doi.org/10.1016/j.trc.2019.03.014.

[15] Carvalho MS, Martins AP, Milho J. Railway seat design for injury mitigation in crash scenario. Int. J. Rail Transp. [Internet]. 2019;00:1-19. Available from: 
https://doi.org/10.1080/23248378.2019.1636318.

[16] Lin T, Wilson NHM. Dwell Time Relationships for Light Rail Systems [Internet]. Transp. Res. Rec. 1992. p. 287-295. Available from: http://trid.trb.org.globalproxy.cvt.dk/view.aspx?id=370918.

[17] Weston JG, McKenna JP. London underground train service model: a description of the model and its uses. Comput. Appl. Railw. Plan. Manag. 1990;133-147.

[18] Harris NG, Anderson RJ. An international comparison of urban rail boarding and alighting rates. Proc. Inst. Mech. Eng. Part F J. Rail Rapid Transit. 2007;221:521-526.

[19] Wirasinghe SC, Szplett D. An investigation of passenger interchange and train standing time at LRT stations: (ii) Estimation of Standing Time. J. Adv. Transp. $1984 ; 18: 1-12$.

[20] Douglas Economics. Modelling Train \& Passenger Capacity. 2012;

[21] Kamizuru T, Noguchi T, Tomii N. Dwell Time Estimation by Passenger Flow Simulation on a Station Platform based on a Multi-Agent Model. RailTokyo2015. 2015;1-15.

[22] Li D, Daamen W, Goverde RMP. Estimation of train dwell time at short stops based on track occupation event data: A study at a Dutch railway station. J. Adv. Transp. [Internet]. 2016;877-896. Available from: http://onlinelibrary.wiley.com/doi/10.1002/atr.144/full.

[23] Hor PS, Idrus MMM. Alighting and Boarding Time Model of Passengers at a LRT Station in Kuala Lumpur. MATEC Web Conf. 2017;103:09011.

[24] D'Acierno L, Botte M, Placido A, et al. Methodology for Determining Dwell Times Consistent with Passenger Flows in the Case of Metro Services. Urban Rail Transit. 2017;3:73-89. 
[25] San HP, Masirin MIM. Train Dwell Time Models for Rail Passenger Service. MATEC Web Conf. 2016;47:03005.

[26] Fernandez R, Zegers P, Weber G, et al. Influence of Platform Height, Door Width, and Fare Collection on Bus Dwell Time . Laboratory Evidence for Santiago de Chile. 2010;

[27] Rudloff C, Bauer D, Matyus T, et al. Mind the gap: Boarding and alighting processes using the social force paradigm calibrated on experimental data. IEEE Conf. Intell. Transp. Syst. Proceedings, ITSC. 2011;353-358.

[28] Fujiyama T, Thoreau R, Tyler N. The effects of the design factors of the trainplatform interface on pedestrian flow rates. Pedestr. Evacuation Dyn. 2012. Springer; 2014. p. 1163-1173.

[29] Fujiyama T, Nowers J, Tyler N. Investigation into Train Dwell Time. 2008;

[30] Fernández R, Valencia A, Seriani S. On passenger saturation flow in public transport doors. Transp. Res. Part A Policy Pract. 2015;78:102-112.

[31] Fujiyama T, Childs C, Boampong D, et al. Investigating ramp gradients for humps on railway platforms. Proc. Inst. Civ. Eng. Munic. Eng. 2015;168:150160.

[32] Holloway C, Thoreau R, Roan TR, et al. Effect of vertical step height on boarding and alighting time of train passengers. Proc. Inst. Mech. Eng. Part F J. Rail Rapid Transit. 2015;230:1234-1241.

[33] Daamen W, Lee Y, Wiggenraad P. Boarding and Alighting Experiments: Overview of Setup and Performance and Some Preliminary Results. Transp. Res. Rec. J. Transp. Res. Board. 2008;2042:71-81.

[34] Rodríguez G de A, Seriani S, Holloway C. Impact of Platform Edge Doors on Passengers' Boarding and Alighting Time and Platform Behavior. Transp. Res. 
Rec. J. Transp. Res. Board. 2016;2540:102-110.

[35] Seriani S, Fujiyama T, Holloway C. Exploring the pedestrian level of interaction on platform conflict areas at metro stations by real-scale laboratory experiments. Transp. Plan. Technol. 2017;40:100-118.

[36] Seriani S, Fujiyama T. Experimental Study for Estimating the Passenger Space at Metro Stations with Platform Edge Doors. Transp. Res. Rec. 2018;

[37] Seriani S, Fernandez R, Luangboriboon N, et al. Exploring the Effect of Boarding and Alighting Ratio on Passengers' Behaviour at Metro Stations by Laboratory Experiments. J. Adv. Transp. 2019;2019.

[38] Fruin JJ. Designing for pedestrians: a level-of-service concept. Highw. Res. Rec. 377. 1971;1-15.

[39] Virkler R, Elayadath S. Pedestrian Speed-Flow-Density Relationships. Transp. Res. Rec. 1992;1438.

[40] Lam WHK, Morall JF, Ho H. Pedestrian flow characteristics in Hong Kong. Transp. Res. Rec. [Internet]. 1995;56-62. Available from: http://onlinepubs.trb.org/Onlinepubs/trr/1995/1487/1487009.pdf\%0Ahttp://onlinepubs.trb.org/Onlinepubs/trr/1995/1487/1487003.pdf\%0Ahttp://cat.inist.fr/?aModele=afficheN\&cpsidt=2946920.

[41] Tanaboriboon Y, Hwa SS, Chor CH. Pedestrian Characteristics Study in Singapore. J. Transp. Eng. 1986;112:229-235.

[42] Hongfei J, Lili Y, Ming T. Pedestrian Flow Characteristics Analysis and Model Parameter Calibration in Comprehensive Transport Terminal. J. Transp. Syst. Eng. Inf. Technol. [Internet]. 2009;9:117-123. Available from: http://dx.doi.org/10.1016/S1570-6672(08)60082-3.

[43] Rastogi R, Ilango T, Chandra S. Pedestrian flow characteristics for different 
pedestrian facilities and situations. Eur. Transp. - Trasp. Eur. 2013;1-21.

[44] Laxman KK, Rastogi R, Chandra S. Pedestrian Flow Characteristics in Mixed Traffic Conditions. J. Urban Plan. Dev. 2010;136:23-33.

[45] Vanumu LD, Ramachandra Rao K, Tiwari G. Fundamental diagrams of pedestrian flow characteristics: A review. Eur. Transp. Res. Rev. 2017;9.

[46] Daamen W, Hoogendoorn SP. Experimental Research of Pedestrian Walking Behavior. Transp. Res. Rec. J. Transp. Res. Board. 2003;1828:20-30.

[47] Hoogendoorn SP, Daamen W. Pedestrian Behavior at Bottlenecks. Transp. Sci. 2005;39:147-159.

[48] Seyfried A, Rupprecht T, Passon O, et al. New insights into pedestrian flow through bottlenecks. Transp. Sci. [Internet]. 2007; Available from: http://arxiv.org/abs/physics/0702004.

[49] Tian W, Song W, Lü W, et al. Experiment and analysis on microscopic characteristics of pedestrian movement in building bottleneck. Sci. China Technol. Sci. 2011;54:1730-1736.

[50] Løvås G. Modeling and simulation of pedestrian traffic flow. Transp. Res. Part B Methodol. 1994;288:429-443.

[51] Mitchell DH, Smith JMG. Topological network design of pedestrian networks David. Transp. Res. Part B. 2001;35:107-135.

[52] Daamen W. Modelling Passenger Flows in Public Transport Facilities [Internet]. Delft Univ. Press. 2004. Available from: http://www.narcis.nl/publication/RecordID/oai:tudelft.nl:uuid:e65fb66c-1e554e63-8c49-5199d40f60e1.

[53] Galiza R, Kim I, Ferreira L, et al. Modelling Pedestrian Circulation in Rail Transit Stations Using Micro-Simulation. 2009;1-24. 
[54] Ding Q, Wang X, Shan Q, et al. Modeling and Simulation of Rail Transit Pedestrian Flow. J. Transp. Syst. Eng. Inf. Technol. [Internet]. 2011;11:99-106. Available from: http://dx.doi.org/10.1016/S1570-6672(10)60145-6.

[55] Xu X yue, Liu J, Li H ying, et al. Analysis of subway station capacity with the use of queueing theory. Transp. Res. Part C Emerg. Technol. [Internet]. 2014;38:28-43. Available from: http://dx.doi.org/10.1016/j.trc.2013.10.010.

[56] Xu X yue, Liu J, Li H ying, et al. Capacity-oriented passenger flow control under uncertain demand: Algorithm development and real-world case study. Transp. Res. Part E Logist. Transp. Rev. [Internet]. 2016;87:130-148. Available from: http://dx.doi.org/10.1016/j.tre.2016.01.004.

[57] Lam WHK, Cheung C-Y, Lam CF. A study of crowding effects at the Hong Kong light rail transit stations. Transp. Res. Part A Policy Pract. [Internet]. 1999;33:401-415. Available from: http://www.scopus.com/inward/record.url?eid=2-s2.00032790886\&partnerID=40\&md5=ee364f8071a1dc87a1ad6d78c4949a71.

[58] RSSB. Management of on-train crowding Final Report. London. 2008.

[59] Oliveira LC, Fox C, Birrell S, et al. Analysing passengers' behaviours when boarding trains to improve rail infrastructure and technology. Robot. Comput. Integr. Manuf. [Internet]. 2019;57:282-291. Available from: https://doi.org/10.1016/j.rcim.2018.12.008.

[60] Preston J, Pritchard J, Waterson B. Train overcrowding: Investigation of the provision of better information to mitigate the issues [Internet]. Transp. Res. Rec. 2017. p. 1-10. Available from: https://www.scopus.com/inward/record.uri?eid=2-s2.0$85015103099 \&$ doi $=10.3141 \% 2 F 2649$ - 
01\&partnerID=40\&md5=a2cdca06f674f049617028ba158bbea5.

[61] LU. Station planning standards and guidelines. Mayor London, Transp. London. $2012 ; 73$

[62] Wiggenraad PBL. Alighting and boarding times of passengers at Dutch railway stations analysis of data collected at 7 stations in October 2000. TRAIL Res. Sch. Delft Univ. Technol. Delft. 2001;

[63] Arup. Farringdon observation and analysis of passenger movements (and flow rates) across the train/platform interface. Final report - Results and analysis, internal report submitted to Department for Transport. 2008.

[64] Jaiswal S, Bunker J, Ferreira L. Relating bus dwell time and platform crowding at a Busway station. 31st Australas. Transp. Res. Forum, ATRF 2008. 2008;2008:239-249.

[65] Childs C, Fujiyama T, Brown I, et al. Pedestrian Accessibility and Mobility Environment Laboratory. Pap. Present. 6th Int. Conf. Walk. 21st Century. 2005.

[66] LU. Rolling Stock Information Sheets. 2007.

Figure 1. Mock-up Carriage Layout [29]

Figure 2. Participants Age Distribution [29]

Figure 3. 5s Interval Boarding Rate and Average Vestibule Density Against the Time from Door Opening

Figure 4. Vestibule Density vs Boarding Rate

Figure 5. Box Plot of Vestibule Density vs 5s Interval Boarding Rate

Figure 6. Vestibule Density vs Boarding Rate in Each Time Interval 